\title{
Hydroxychloroquine and COVID-19: a Rheumatologist's Take on the Lessons Learned
}

\author{
Akrithi Udupa $^{1} \cdot$ David Leverenz $^{1} \cdot$ Stephen J. Balevic ${ }^{1} \cdot$ Rebecca E. Sadun $^{1} \cdot$ Teresa K. Tarrant $^{1} \cdot$ Jennifer L. Rogers ${ }^{1}$ \\ Accepted: 5 December 2020 / Published online: 21 January 2021 \\ (C) The Author(s), under exclusive licence to Springer Science+Business Media, LLC part of Springer Nature 2021
}

\begin{abstract}
Purpose of Review Told from the viewpoint of rheumatologists, this review tells the story of hydroxychloroquine and its swift ascent to become a household name as a therapeutic strategy against the novel SARS-CoV-2 virus. This review describes the history, mechanisms, pharmacokinetics, therapeutic applications, and safety profile of hydroxychloroquine as an immunomodulatory and antiviral agent. It also summarizes the major studies that launched and assessed the use of hydroxychloroquine against COVID-19 infection.

Recent Findings More recent literature calls into question the long-held dogma that endolysosomal alkalinization is the primary mode of action of hydroxychloroquine. Ongoing uncertainty about the multiple potential mechanisms contributing to the therapeutic effect of hydroxychloroquine in rheumatic and viral disease led to a natural avenue for exploration in the treatment of COVID-19. Taken as a whole, the literature does not support utilizing hydroxychloroquine to treat or prevent infection from the SARS-CoV-2 virus. This is, at least in part, due to the wide variability in hydroxychloroquine pharmacokinetics between patients and difficulty achieving adequate target tissue concentrations of hydroxychloroquine without encountering unacceptable toxicities. Summary Hydroxychloroquine continues to be a routinely prescribed, well-tolerated, effective, and low-cost treatment for rheumatic disease. Its therapeutic versatility has led to frequent repurposing for other conditions, most recently as an investigative treatment against the SARS-CoV-2 virus. Despite overall negative findings, the intense study of hydroxychloroquine against COVID-19 infection has enhanced our overall understanding of how hydroxychloroquine operates in autoimmune disease and beyond.
\end{abstract}

Keywords Hydroxychloroquine $\cdot$ COVID-19 $\cdot$ SARS-CoV-2 $\cdot$ Immunomodulation

\section{Introduction}

Following the initial recognition of coronavirus disease 2019 (COVID-19) caused by novel SARS-CoV-2 virus in December of 2019, confirmed cases rose exponentially to reach global pandemic status by March of 2020, adding urgency to quest for safe and effective treatments [1]. As a result, a number of existing medications were repurposed to manage this infection [2]. Among these off-label therapies, hydroxychloroquine (HCQ) quickly rose to the world stage as a promising candidate. In the pre-COVID-19 era, infectious disease specialists and rheumatologists routinely prescribed

Akrithi Udupa

akrithi.udupa@duke.edu

1 Duke University Medical Center, Box 2978, Durham, NC 27710, USA
HCQ for its antimicrobial and immunomodulatory properties, excellent safety profile, and low cost. Herein we will review the historical context and mechanistic considerations underlying the attempt to use HCQ in viral diseases, followed by an update on the observational and clinical trial data evaluating its efficacy in COVID-19. As rheumatologists, we recognize that despite all of the controversy, politicizing, and ethical quandaries surrounding HCQ in COVID-19, this moment has provided greater insight into the workings of a therapeutic cornerstone in our field, and careful attention to this literature can inform not only our own practice but also the practice of others interested in repurposing this drug in the future.

\section{History and Clinical Applications}

Throughout history, the antimalarial HCQ and its predecessors quinine, quinacrine, and chloroquine (CQ) have proven to be therapeutically versatile [3]. In 1820, quinine was 
extracted from cinchona bark, which was first documented as curing fevers in the 1630s and broadly utilized over the next two centuries as a medicinal cure-all [3]. Quinacrine was introduced for malaria treatment in the 1930s, and World War II soldiers taking quinacrine were incidentally observed to have an improvement in cutaneous lupus and inflammatory arthritis leading to a landmark case series published in the Lancet detailing the success of mepacrine, another name for quinacrine, in treating systemic lupus erythematosus [4]. In the 1940s, CQ emerged as an antiparasitic and later gained traction in a wide array of other infectious diseases as it became less effective in treating the rising number of CQ-resistant malaria strains [5].

The synthesis of HCQ in 1946 by American chemists Alexander Surrey and Henry Hammer provided a conveniently produced, economical, safe, and better tolerated medication than its immediate parent drug CQ [3, 6]. First approved for use in 1955, HCQ is currently approved by the US Food and Drug Administration to treat malaria, discoid and systemic lupus erythematosus, and rheumatoid arthritis [7, 8]. However, numerous off-label uses exist including cutaneous dermatomyositis, extra-glandular manifestations of Sjogren's syndrome, sarcoidosis, antiphospholipid syndrome, porphyria cutanea tarda, and Q fever [9-12]. The far-reaching therapeutic range of HCQ is partially due to its unique and highly variable pharmacokinetic profile as well as its multiple proposed mechanisms of action.

\section{Structure and Pharmacokinetics}

Hydroxychloroquine is a 4-aminoquinoline comprised of two aromatic rings [6]. It is a weak base that is mostly absorbed in the upper gastrointestinal tract with approximate oral bioavailability of $70 \%$, although there is wide between-patient variability in the extent of absorption [13-15]. Hydroxychloroquine is primarily metabolized by cytochrome P450 enzymes in the liver to multiple active metabolites, and up to approximately one-fourth of unchanged drug is eliminated through the kidneys $[8,15]$. While there are no specific guidelines for dose adjustment in hepatic and renal impairment, the updated American Academy of Ophthalmology (AAO) guidelines recognize renal disease, along with using HCQ at high doses for a long period of time, as major risk factors for the development of retinal toxicity [16]. Several properties of HCQ contribute to a high volume of distribution of approximately 40,000 1 including low protein binding (50\%), lipophilicity, and avid tissue binding $[17,18]$. While HCQ accumulates in several tissues, it has an affinity for areas with high melanin content, such as the retinal pigment epithelium [17]. Interestingly, animal data suggests that accumulation within these tissues occurs over a period of several months; this may be one mechanism contributing to the delay in clinical benefit once HCQ is administered [19]. Due to high volume of distribution relative to drug clearance, HCQ has a long terminal elimination half-life, on the order of 40 days [20].

Due to variability in absorption, metabolism, excretion, and other physiologic processes, blood levels of HCQ differ more than 10-fold between patients [21, 22]. This inter-patient pharmacokinetic variability, as well as unpredictable and gradual accumulation within tissues, may explain the differences in how patients respond and length of time to the development of retinal toxicity.

\section{Hydroxychloroquine in Rheumatic Disease}

Across decades, HCQ remains a mainstay pharmacotherapy in the treatment of a variety of rheumatic diseases. Patients with systemic lupus erythematosus who consistently take HCQ experience improvements in overall and disease-free survival, end organ damage accrual, as well as severity and frequency of flares; beyond lupus, patients with rheumatic disease who take HCQ benefit from improvements in their thrombotic risk, lipid profile, and glycemic index [23]. The question of how HCQ results in these benefits, particularly in lupus, remains a topic of great interest and ongoing study. As shown in Fig. 1, HCQ is theorized to disturb autoantigen presentation by major histocompatibility complex class II (MHC class II) cells to $\mathrm{T}$ cells and subsequent $\mathrm{T}$ and $\mathrm{B}$ cell differentiation and maturation $[14,25]$. It is also thought to impair tolllike receptor (TLR) 7 and 9 and cyclic GMP-AMP synthasestimulator of interferon genes (cGAS-STING) signaling pathways, the latter being a significant source of type 1 interferon, ultimately reducing production of proinflammatory cytokines $[14,26]$.

A long-standing theory of how HCQ carries out these functions is lysosomotropism [27]. The lysosome, an acidic subcellular organelle present in most eukaryotic cells, plays a central role in cellular homeostasis and metabolic signaling through both catabolic and anabolic mechanisms [28]. Lysosomes degrade cellular components and macromolecules via the autophagy pathway, endocytosis, and phagocytosis [29*•]. Lysosomal function is dependent on maintenance of an acidic $\mathrm{pH}$. The lysosomotropism concept postulates that basic compounds such as HCQ accumulate inside the lysosome, raising the $\mathrm{pH}$ of the endolysosomal compartment and subsequently disrupting hydrolytic enzymatic functions, autoantigen processing, and downstream signaling [14, 30]. However, more recent literature suggests that lysosomal alkalization is transient following HCQ exposure [30••]. Furthermore, an alternative mechanism that is not dependent on lysosomal alkalinization suggests that HCQ triggers mammalian target of rapamycin complex 1 (mTORC1) and calcium-mediated lysosome biogenesis as a response to stress 
$[30 \bullet \cdot$. Interestingly, it has been demonstrated in lupus-prone mice that chronic activation of mTOR complex 2 (mTORC2) impedes cleavage of Rab39a by caspase- 1 which prevents lysosomal acidification [31]. To expand further, it is thought that lysosomal defects may contribute to aging as well as a number of chronic conditions, including autoimmunity [32]. For example, macrophages from lupus-prone mice have been identified as having immature lysosomes that cannot prevent the accumulation of apoptotic debris containing IgG immune complexes on cell surfaces, thus continuously exposing cytoplasmic sensors to auto-antigen [33•].

Dysregulation of autophagy has also been linked to the pathogenesis of autoimmune disease, and HCQ is one of the two FDA-approved autophagy inhibitors [34•]. Autophagy is the process by which lysosomes fuse with autophagosomes to remove pathogens and breakdown cellular debris and misfolded proteins [35]. It is widely accepted that HCQ impairs autophagic flux, the amount of degraded and recycled cellular material [34•]. Emerging data, however, suggests that CQ and HCQ may disrupt endosome-lysosome fusion independent of the autophagy pathway through derangement of the intracellular compartments [34•]. Our understanding of the likely multiple mechanisms underlying the numerous benefits of HCQ continues to evolve and warrants ongoing study.
Using a chronic daily dosing strategy, HCQ offers reliable and effective immunomodulation while being exceptionally safe and non-immunosuppressive. Typical dosing of HCQ for autoimmune diseases falls between 200 and $400 \mathrm{mg}$ daily, in either single or multiple doses [12]. Updated 2016 AAO HCQ dosing guidelines recommend a maximum of $5 \mathrm{mg} / \mathrm{kg} /$ $\mathrm{d}$, using real body weight, to prevent the adverse effect of irreversible retinopathy, the risk of which is dose and duration dependent at less than $1 \%$ for up to 5 years, but rising to $20 \%$ at 20 years [16]. Anecdotally, the most commonly encountered adverse effects to HCQ in rheumatology clinical practice include gastrointestinal distress and dermatologic reactions. Rare but serious complications include cardiomyopathy, QT prolongation, ventricular arrhythmias, proximal neuropathy and/or myopathy, myelosuppression, and hypoglycemia [12]. HCQ crosses the placenta and is transferred in breast milk, although no major permanent toxicities have been noted in either the fetus or the child $[14,36]$. In fact, the 2020 American College of Rheumatology Reproductive Health Guidelines strongly recommend that women with rheumatic disease continue HCQ through pregnancy and conditionally recommend that pregnant women with positive anti-Ro/La take HCQ to prevent fetal development of congenital heart block [37].

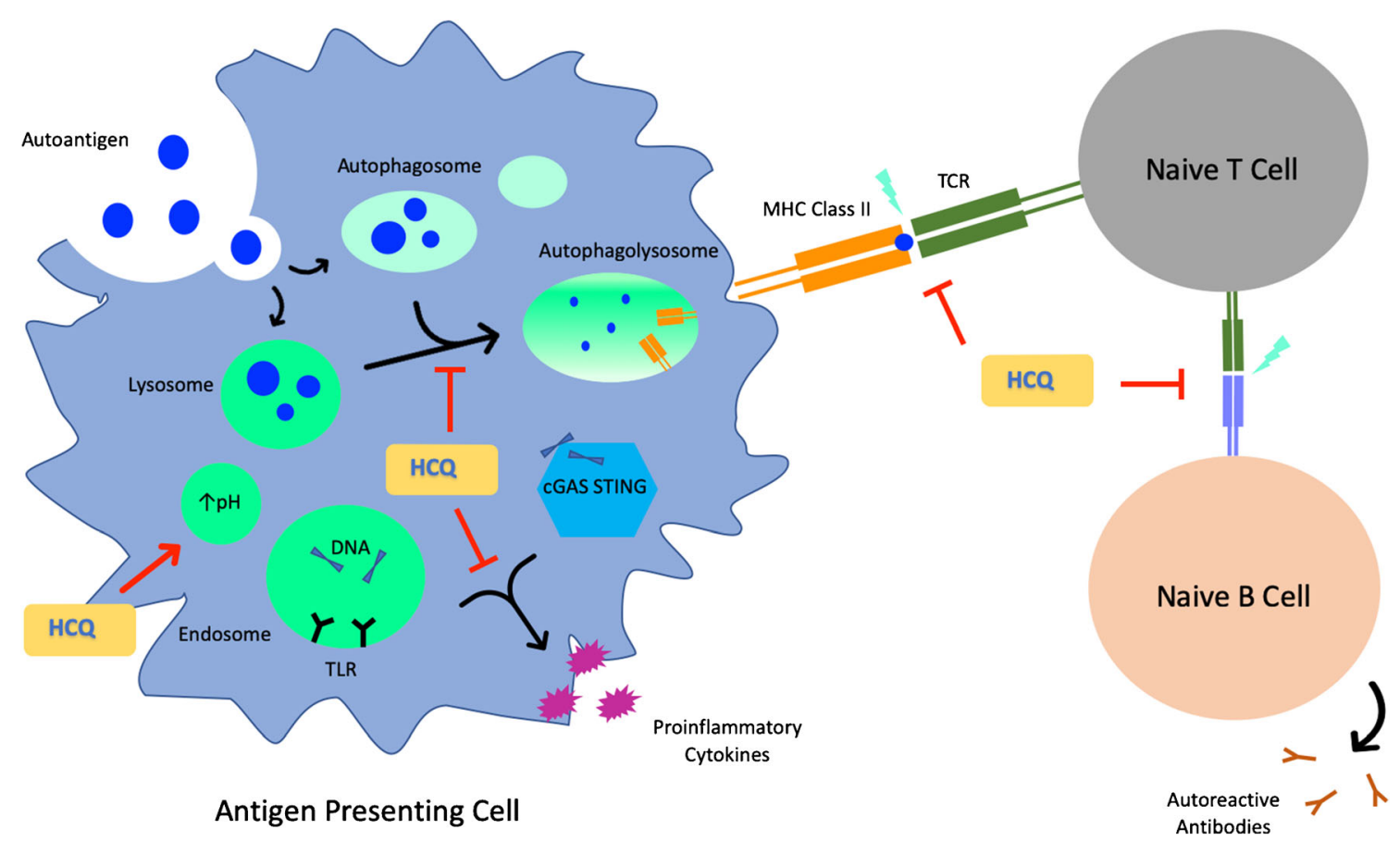

Fig. 1 Major proposed mechanisms of HCQ in autoimmune disease. Figure adapted from Schrezenmeier et al. [14], Wallace et al. [23], and Nirk et al. [24]. (Clockwise from bottom left) HCQ raises the $\mathrm{pH}$ of the lysosomal compartment, inhibiting hydrolytic enzymatic processing of extracellular autoantigen endocytosed by the cell. HCQ raises the $\mathrm{pH}$ of the autophagosomal compartment, inhibiting degradation of intracellular debris and autophagic flux. HCQ hinders fusion of lysosomes with autophagosomes, diminishing successful MHC class II-mediated autoantigen presentation by antigen-presenting cells. HCQ thwarts naïve $\mathrm{T}$ cell and $\mathrm{B}$ cell activation, subsequently decreasing production of autoreactive antibodies. HCQ limits Toll-like receptor signaling and cGAS-STING pathways, lessening production of proinflammatory cytokines. HCQ, hydroxychloroquine; TCR, T cell receptor; cGAS-STING, cyclic GMP-AMP stimulator of interferon genes; TLR, Toll-like receptor 


\section{Hydroxychloroquine as an Antiviral in the Pre-COVID-19 Era}

There has been a long-held interest in repurposing antimalarials like HCQ to treat a variety of viruses. Several potential antiviral mechanisms for HCQ have been proposed, including interfering with viral surface receptor binding, biosynthesis of sialic acids and subsequent ligand recognition, $\mathrm{pH}$ gradientdependent endosome-mediated cell entry and virus-endosome fusion, viral uncoating, posttranslational modification of the viral protein, proteolytic processing, viral budding, and maturation of the viral protein, among others [38]. HCQ also has immunomodulatory effects that are possibly effective against viruses, including improving the transport of viral particles to dendritic presenting cells and subsequent $\mathrm{CD} 8^{+} \mathrm{T}$ cell activation, as well as inhibition of $\mathrm{p} 38$ mitogen-activated protein kinase (MAPK) signaling, which is important for viral replication [38]. Further contributing to a largely antiinflammatory response against pathogens, CQ and HCQ are thought to inhibit TLR 7 and 9 signaling, thus reducing production of pro-inflammatory cytokines and evolution into cytokine storm [14, 34, 38-40].

HCQ has been evaluated as a potential antiviral agent against two particularly notable viruses across history, human immunodeficiency virus (HIV) and influenza [5]. The rationale for researching HCQ as a treatment of HIV included targeting immune activation-mediated decline in CD4 count, delaying or reducing the reliance on antiretroviral therapy (ART) and their potential side effects, and providing a lowcost option in resource scarce areas [41]. Amidst the acquired immunodeficiency syndrome (AIDS) pandemic, Chiang et al. found that not only did both enantiomers of HCQ suppress HIV-1 activity by raising the $\mathrm{pH}$ of the endosomal compartments and inhibiting posttranslational modification of gp120, but also curbed HIV-1 replication in a dose-dependent fashion in both recently and chronically infected $\mathrm{T}$ and monocyte cell lines [42]. Subsequent studies, however, showed conflicting results, including a randomized placebo-controlled trial of 83 asymptomatic HIV-infected patients off of ART who were treated with either HCQ $400 \mathrm{mg}$ daily or placebo daily for 48 weeks, with results showing no significant difference in $\mathrm{CD}^{+} \mathrm{T}$ cell activation, a significant decline in $\mathrm{CD} 4^{+} \mathrm{T}$ cell count, and a significant increase in viral load in the HCQ group compared to the placebo group [41].

Regarding exploration of the therapeutic utility of HCQ for influenza, rising viral strain resistance against adamantanes (i.e., oseltamivir) around the world led to a push to identify new drugs with antiviral properties against influenza A and B [43]. Shibata and colleagues discovered that $\mathrm{CQ}$ raised the $\mathrm{pH}$ beyond the point where the viral envelope of Influenza B could successfully fuse with the lysosome in canine kidney cells, thus hampering viral uncoating [44]. However, later studies identified inconsistencies, even going so far as to say that chloroquine enhanced influenza A replication in vitro [45].

In 2002, at the onset of the severe acute respiratory syndrome (SARS) pandemic due to SARS coronavirus (SARS$\mathrm{CoV}$ ), efforts were made to swiftly determine the viral mechanism as well as a safe and effective treatment [46]. Li et al. found that angiotensin-converting enzyme 2 (ACE2) was a functional receptor of the $\mathrm{S} 1$ domain on the SARS-CoV spike (S) protein [47]. Vincent et al. found that CQ disrupts viral spread of SARS-CoV both pre-infection ( $24 \mathrm{~h}$ prior) and postinfection ( 3 to $5 \mathrm{~h}$ after) in Vero E6 cells in a dose-dependent manner [46]. This group-theorized CQ accomplished this through terminal glycosylation of ACE2, thus reducing its affinity to bind the $\mathrm{S}$ protein and interfering with onset of infection [46]. It is worth noting that Vero E6 cells are kidney epithelial cells from the African Green Monkey which are interferon deficient; these cells are ideal clones for achieving high viral nucleic acid copies but do not necessarily mimic the physiologic conditions of the respiratory epithelium in vivo [48]. By mid-2003, SARS was felt to be contained, somewhat slowing further investigation into new therapeutic agents and preventative vaccines [49].

\section{Hydroxychloroquine as an Antiviral in the COVID-19 Era}

As of mid-September 2020, COVID-19 is proving to be a far more formidable disease than SARS, approaching nearly 30 million cases and 1 million deaths worldwide [50]. Based on prior data supporting its use in SARS-CoV virus as well as the hypotheses that HCQ could inhibit viral replication due to lysosomal deacidification and the ability to prevent progression into cytokine storm, HCQ was repurposed as an investigational therapy to treat the SARS-CoV-2 virus.

Early in vitro studies attempted to identify the effective concentration of HCQ needed to inhibit half $\left(\mathrm{EC}_{50}\right)$ of SARS-COV-2 viral replication [51, 52]. These in vitro targets were then used for pharmacokinetic/pharmacodynamic (PK/ PD) modeling to establish the target HCQ doses needed to achieve antiviral activity against SARS-CoV-2 infection [51]. However, the researchers likely did not account for the differences between the in vitro assay and the in vivo target tissue $[53,54]$. Specifically, the in vitro assay mimics the amount of free HCQ in plasma or extracellular fluid, whereas HCQ's in vivo antiviral activity requires adequate intracellular concentrations within target tissues, which for coronaviruses is thought to be respiratory tract epithelial cells [53, 55]. Accounting for these discrepancies, investigators from the FDA published an analysis demonstrating that free intracellular HCQ concentrations in lung tissue is predicted to be 10 to 100 times lower than in vitro $\mathrm{EC}_{50}$ targets, and therefore, it is unlikely that we can safely administer the doses of HCQ 
necessary to achieve antiviral activity against SARS-CoV-2 in vivo $[53 \bullet \bullet$.

During one of the earliest prospective cohort analyses of COVID-19 patients in February of 2020, Huang et al. noted that patients infected with SARS-CoV-2 virus had a highly proinflammatory cytokine profile and that elevations in some of these cytokines, such as granulocyte colony-stimulating factor (G-CSF) and tumor necrosis factor-alpha (TNF- $\alpha$ ), were predictive of more severe disease [56]. Shortly thereafter, Chen et al. performed a retrospective review of COVID19 patients, noting significantly higher levels of proinflammatory molecules, including interleukin-2 receptor (IL-2R) and interleukin-6 (IL-6), significantly lower $\mathrm{CD}^{+} \mathrm{T}$ cells and $\mathrm{CD}^{+} \mathrm{T}$ cells, significantly lower naïve

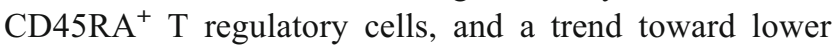
natural killer cells in severe cases as compared to moderate cases [57•]. These studies highlight the ways in which hyperinflammation and immune system dysfunction contribute to the pathogenesis of COVID-19 [58]. In theory, immune-modulating therapies such as HCQ could help tip the immune response toward a less inflammatory state, curb production of proinflammatory cytokines, and prevent progression to a deadly cytokine storm.

Following initial in vitro studies suggesting the possible utility of HCQ against COVID-19, numerous observational and clinical trials began to explore its efficacy and safety in humans (Table 1). A pivotal initial study published on March 20, 2020, by Gautret et al. reported on 42 patients with or without exposure to $\mathrm{HCQ}$, suggesting lower viral carriage in those treated with HCQ and particularly low viral carriage in those treated with both HCQ and azithromycin. Importantly, clinical efficacy endpoints beyond nasal carriage were not discussed [59]. Many raised concerns about methodological flaws in this study, including the lack of randomization and the exclusion of 6 patients treated with HCQ who were lost to follow-up due to ICU transfer (3 patients), death (1 patient), leaving the hospital (1 patient), and treatment discontinuation (1 patient). Despite these concerns, this study received international attention and spurred many to use this medication despite the absence of a randomized, placebo-controlled clinical trial.

Over the next several months, numerous pre-print studies that had not yet undergone peer review were rapidly posted to open-access servers such as MedRxiv.org. These pre-prints allowed the rapid dispersion of study results but also led to many questions regarding each report's methodology and accuracy, especially in light of their often-conflicting findings. Some of the most highly cited articles were pre-print studies, including a randomized controlled trial in 62 patients suggesting efficacy of HCQ for COVID-19 [71] and a very recently published observational study from the US Veterans Health
Administration health system that suggested an association between HCQ and increased overall mortality in hospitalized patients with COVID-19 [72]. Observational studies published in peer-reviewed journals also reported conflicting findings, and further confusion ensued after the infamous retraction of a major observational study published in The Lancet, following concerns about the credibility of the data used in its analysis.

The first major randomized controlled trial examining HCQ in COVID-19 published in the peer-reviewed literature appeared on May 6, 2020, by Tang et al [65]. This study compared HCQ with standard of care in 150 hospitalized patients with COVID-19 across 16 medical centers in China, finding no difference in the negative conversion rate of SARS-CoV-2 by 28 days [65]. Subsequently, multiple additional randomizedcontrolled trials have replicated these findings in hospitalized patients, while also demonstrating lack of efficacy for postexposure prophylaxis or in outpatients with mild infections. Other major studies have been halted due to lack of efficacy, including the HCQ arm of the World Health Organization SOLIDARITY trial, the UK National Institute for Health Research RECOVERY trial, and the US National Institutes of Health ORCHID trial. On June 15, 2020, the US FDA revoked the Emergency Use Authorization that permitted the use of chloroquine and hydroxychloroquine from the national stockpile for hospitalized patients. Overall, though many ongoing trials have yet to report results, clinical evidence is rapidly accumulating that HCQ is not effective for the treatment or prevention of COVID-19.

\section{Conclusions}

As rheumatologists, we have few remedies in our armamentarium that can match the therapeutic utility, safety profile, and accessibility of HCQ. Patients of all ages and ethnicities with an array of underlying autoimmune conditions take HCQ with a high level of tolerability; this ultimately allows for long-term dosing, maximizing its immunomodulatory yet non-immunosuppressive effects. Despite clinical use for nearly three quarters of a century, the exact mechanisms of HCQ in autoimmune and viral diseases remain uncertain. In autoimmune disease, HCQ has been shown to impair TLR and cGAS-STING signaling pathways, disrupt endosomelysosome fusion, and disturb autoantigen presentation by MHC class II to T cells. A number of antiviral mechanisms have been suggested, postulating that both CQ and HCQ are able to interfere with nearly every step of the viral life cycle. The long-standing dogma that HCQ primarily functions through $\mathrm{pH}$ gradient-dependent lysosomotropism and endolysosomal alkalinization has come into question as lysosomal acidification may be transient and lysosomes are now 


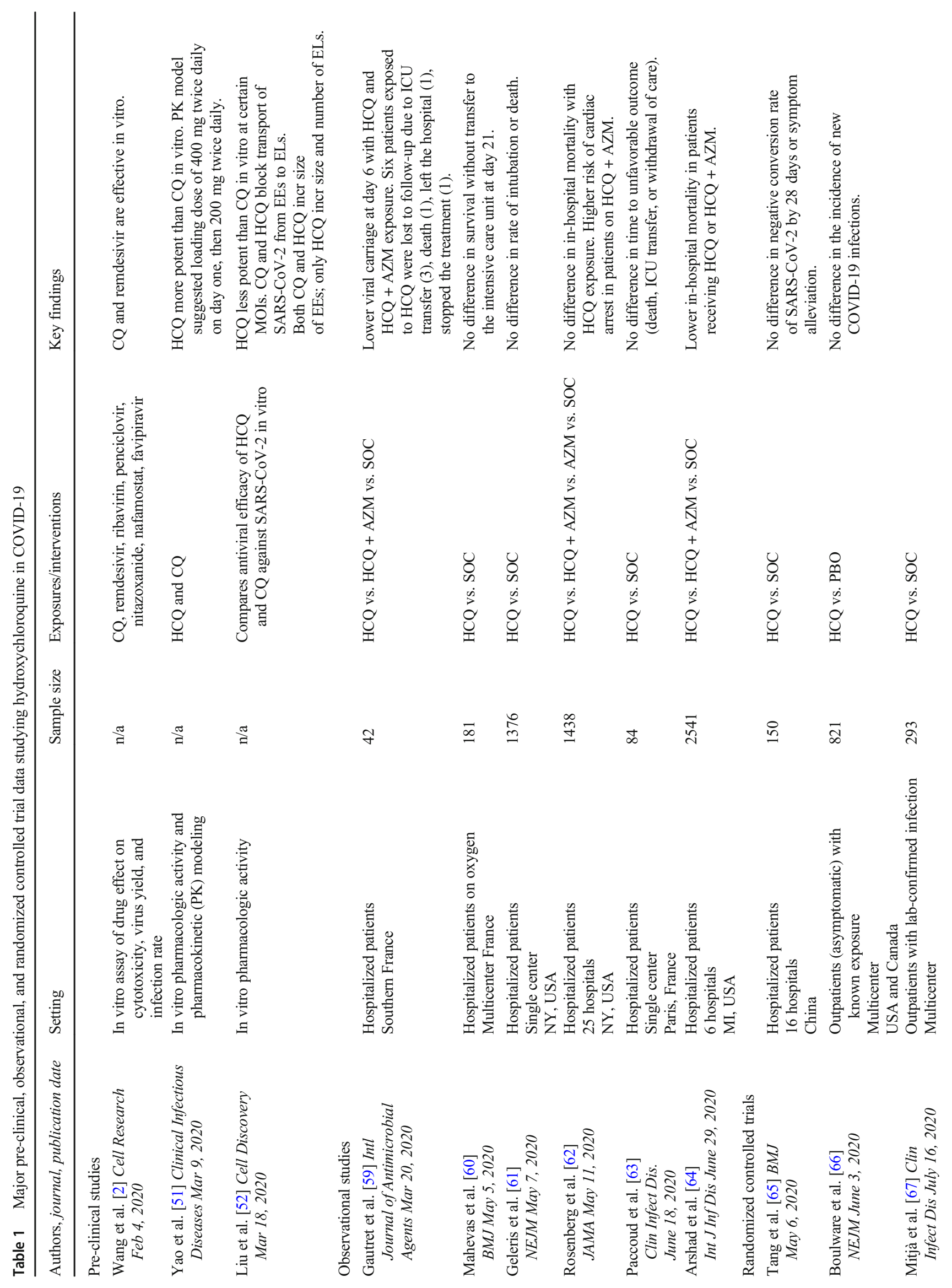




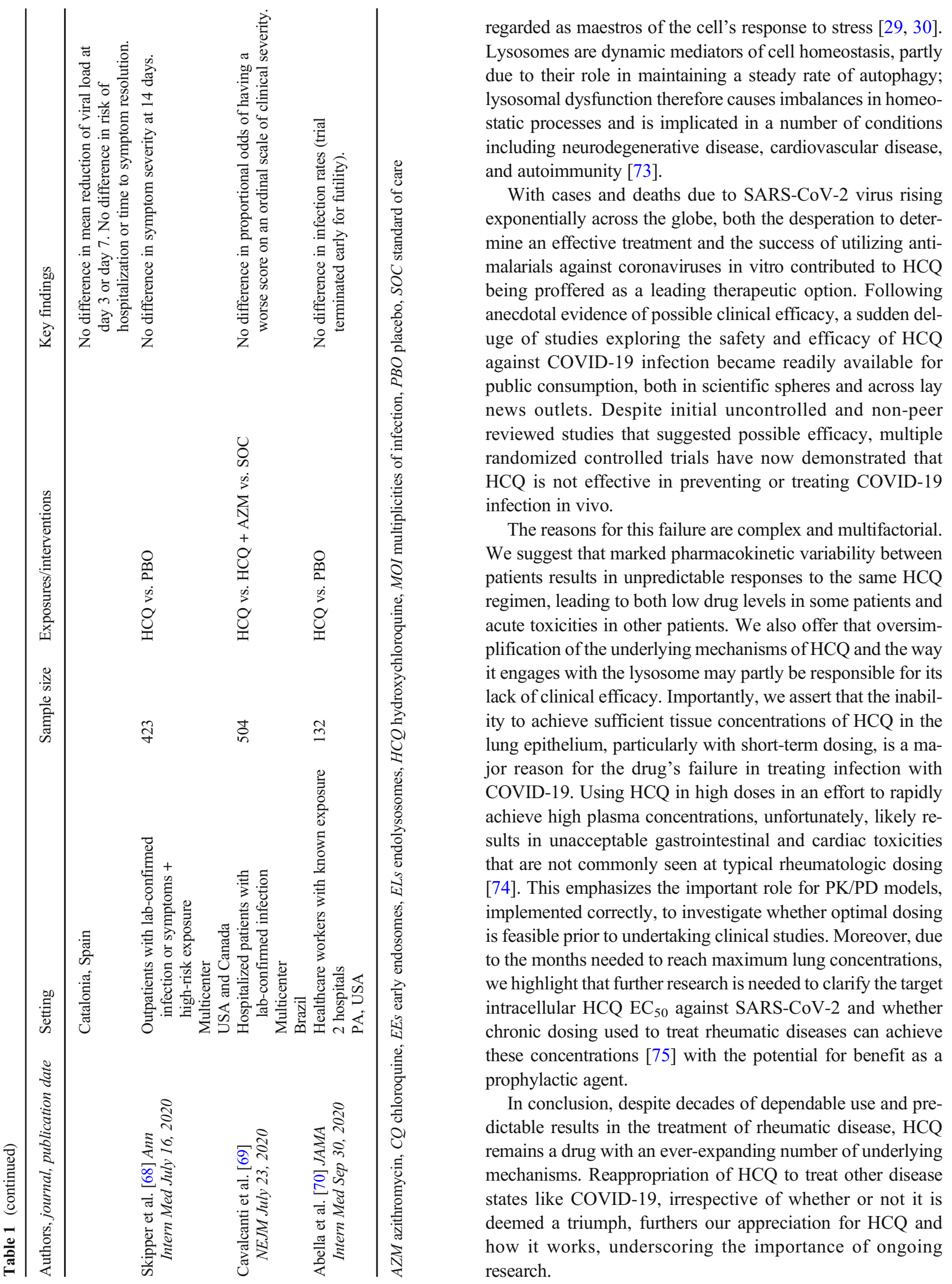




\section{Compliance with Ethical Standards}

Conflict of Interest The authors declare no conflicts of interest relevant to this manuscript.

Human and Animal Rights and Informed Consent This article does not contain any studies with human or animal subjects performed by any of the authors.

\section{References}

Papers of particular interest, published recently, have been highlighted as:

- Of importance

•- Of major importance

1. WHO. Timeline of WHO's response to COVID-19: World Health Organization [Internet]. 2020. Available from: https://www.who. int/news-room/detail/29-06-2020-covidtimeline.

2. Wang M, Cao R, Zhang L, Yang X, Liu J, Xu M, et al. Remdesivir and chloroquine effectively inhibit the recently emerged novel coronavirus (2019-nCoV) in vitro. Cell Res. 2020;30(3):269-71. Available from: https://doi.org/10.1038/ s41422-020-0282-0.

3. Isaacson D, Elgart M, Turner ML. Anti-malarials in dermatology. Int J Dermatol. 1982;21(7):379-95. Available from: https://doi.org/ 10.1111/j.1365-4362.1982.tb03155.x, 1982.

4. Page F. Treatment of lupus erythematosus with mepacrine. Lancet. 1951;2(6687):755-8. Available from: https://doi.org/10.1016/ S0140-6736(51)91643-1, 1951.

5. Rolain JM, Colson P, Raoult D. Recycling of chloroquine and its hydroxyl analogue to face bacterial, fungal and viral infections in the 21st century. Int J Antimicrob Agents. 2007;30(4):297-308. Available from: https://doi.org/10.1016/j.ijantimicag.2007.05.015, 2007.

6. Surrey AR, Hammer HF. Some 7-substituted 4-aminoquinoline derivatives. J Am Chem Soc. 1946;68:113-6. Available from: https://doi.org/10.1021/ja01205a036.

7. Avdic E. Hydroxychloroquine [Internet]. In: Johns Hopkins ABX Guide. The Johns Hopkins University; 2020. Available from: https://www.hopkinsguides.com/hopkins/view/Johns_Hopkins ABX_Guide/540748/all/Hydroxychloroquine.

8. Concordia Pharmaceuticals Inc. Plaquenil, Hydroxychloroquine Sulfate Tablets, USP [Internet]. U.S. Food and Drug Administration website; 2015. Available from: https://www. accessdata.fda.gov/drugsatfda_docs/label/2017/ 009768s037s045s047lbl.pdf.

9. Wallace DJ. Antimalarial drugs in the treatment of rheumatic disease [internet]. UpToDate; 2020. Available from: https://www. uptodate.com/contents/antimalarial-drugs-in-the-treatment-ofrheumatic-disease.

10. Singal AK, Anderson KE. Porphyria cutanea tarda and hepatoerythropoietic porphyria: management and prognosis [Internet]. UpToDate; 2019. Available from: https://www. uptodate.com/contents/porphyria-cutanea-tarda-andhepatoerythropoietic-porphyria-pathogenesis-clinicalmanifestations-and-diagnosis.

11. Anderson, A et. al. Diagnosis and Management of Q Fever United States, 2013: Recommendations from CDC and the Q Fever Working Group [Internet]. CDC; 2013. Available from: https://www.cdc.gov/mmwr/preview/mmwrhtml/rr6203a1.htm.
12. Lexicomp. Hydroxychloroquine: Drug Information [Internet]. UpToDate; 2020. Available from: https://www.uptodate.com/ contents/hydroxychloroquine-drug-information.

13. Tett SE, Cutler DJ, Day RO, Brown KF. Bioavailability of hydroxychloroquine tablets in healthy volunteers. Br J Clin Pharmacol. 1989;27(6):771-9. Available from: https://doi.org/10. 1111/j.1365-2125.1989.tb03439.x, 1989.

14. Schrezenmeier, E., Dörner, T. Mechanisms of action of hydroxychloroquine and chloroquine: implications for rheumatology. Nat Rev Rheumatol. 2020; 155-166. Available from: https:// doi.org/10.1038/s41584-020-0372-x.

15. Rainsford KD, Parke AL, Clifford-Rashotte M, Kean WF. Therapy and pharmacological properties of hydroxychloroquine and chloroquine in treatment of systemic lupus erythematosus, rheumatoid arthritis and related diseases. Inflammopharmacology. 2015;23(5): 231-69. Available form: https://doi.org/10.1007/s10787-015-0239y, 2015.

16. Ophthalmology AAo. Recommendations on Screening for Chloroquine and Hydroxychloroquine Retinopathy - 2016 [Internet]. AAO Quality of Care Secretariat, Hoskins Center for Quality Eye Care: American Academy of Ophthalmology; 2016. p. 1386-1394. Available from: https://www.aao.org/clinicalstatement/revised-recommendations-on-screening-chloroquine-h.

17. Browning, DJ et. al. Pharmacology of chloroquine and hydroxychloroquine. In: Hydroxychloroquine and chloroquine retinopathy. Springer, New York, NY; 2014. Available from: https:// doi.org/10.1007/978-1-4939-0597-3_2.

18. Mackenzie AH. Pharmacologic actions of 4-aminoquinoline compounds. Am J Med. 1983;75(1A):5-10. Available from: https://doi. org/10.1016/0002-9343(83)91264-0, 1983.

19. McChesney EW. Animal toxicity and pharmacokinetics of hydroxychloroquine sulfate. Am J Med. 1983;75(1A):11-8. Available from: https://doi.org/10.1016/0002-9343(83)91265-2, 1983.

20. Tett SE, Cutler DJ, Day RO, Brown KF. A dose-ranging study of the pharmacokinetics of hydroxy-chloroquine following intravenous administration to healthy volunteers. Br J Clin Pharmacol. 1988;26(3):303-13. Available from: https://doi.org/10.1111/j. 1365-2125.1988.tb05281.x, 1988.

21. Costedoat-Chalumeau N, LE Guern V, Piette JC. Routine hydroxychloroquine blood concentration measurement in systemic lupus erythematosus reaches adulthood. J Rheumatol. 2015;42(11): 1997-9. Available from: https://doi.org/10.3899/jrheum.151094, 2015.

22. Tett S, Day R, Cutler D. Hydroxychloroquine relative bioavailability: within subject reproducibility. Br J Clin Pharmacol. 1996;41(3): 244-6. Available from: https://doi.org/10.1111/j.1365-2125.1996. tb00190.x, 1996.

23. Wallace DJ, Gudsoorkar VS, Weisman MH, Venuturupalli SR. New insights into mechanisms of therapeutic effects of antimalarial agents in SLE. Nat Rev Rheumatol. 2012;8(9):522-33. Available: https://doi.org/10.1038/nrrheum.2012.106, 2012.

24. Nirk EL, Reggiori F, Mauthe M. Hydroxychloroquine in rheumatic autoimmune disorders and beyond. EMBO Mol Med. 2020;12(8): e12476. Available from: https://doi.org/10.15252/emmm. 202012476.

25. Fox RI. Mechanism of action of hydroxychloroquine as an antirheumatic drug. Semin Arthritis Rheum. 1993;23(2 Suppl 1):8291. Available from: https://doi.org/10.1016/S0049-0172(10) 80012-5, 1993.

26. An J, Woodward JJ, Sasaki T, Minie M, Elkon KB. Cutting edge: antimalarial drugs inhibit IFN- $\beta$ production through blockade of cyclic GMP-AMP synthase-DNA interaction. J Immunol. 2015;194(9):4089-93. Available from: https://doi.org/10.4049/ jimmunol.1402793, 2015. 
27. de Duve C, de Barsy T, Poole B, Trouet A, Tulkens P, Van Hoof F. Commentary. Lysosomotropic agents. Biochem Pharmacol. 1974;23(18):2495-531. Available from: https://doi.org/10.1016/ 0006-2952(74)90174-9, 1974.

28. Perera RM, Zoncu R. The lysosome as a regulatory hub. Annu Rev Cell Dev Biol. 2016;32:223-53. Available from: https://doi.org/10. 1146/annurev-cellbio-111315-125125, 2016.

29. Lamming DW, Bar-Peled L. Lysosome: the metabolic signaling hub. Traffic. 2019;20(1):27-38. Available from: https://doi.org/ 10.1111 tra.12617. Identifies the lysosome as a dynamic organelle that is integral to coordinating numerous signaling pathways. If the lysosome is dysregulated, human pathology can result.

30.• Lu S, Sung T, Lin N, Abraham RT, Jessen BA. Lysosomal adaptation: how cells respond to lysosomotropic compounds. PLoS one. 2017;12(3):e0173771. Available from: https://doi.org/10.1371/ journal.pone.0173771. Demonstrates the transience of lysosomal pH increase and proposes alternative HCQ mechanisms.

31. Monteith AJ, Vincent HA, Kang S, Li P, Claiborne TM, Rajfur Z, et al. mTORC2 activity disrupts lysosome acidification in systemic lupus erythematosus by impairing caspase-1 cleavage of Rab39a. J Immunol. 2018;201(2):371-82. Available from: https://doi.org/10. 4049/jimmunol.1701712, 2018.

32. Levine B, Kroemer G. Autophagy in the pathogenesis of disease. Cell. 2008;132(1):27-42. Available from: https://doi.org/10.1016/j. cell.2007.12.018, 2008.

33. Monteith AJ, Kang S, Scott E, Hillman K, Rajfur Z, Jacobson K, et al. Defects in lysosomal maturation facilitate the activation of innate sensors in systemic lupus erythematosus. Proc Natl Acad Sci U S a. 2016;113(15):E2142-51. Available from: https://doi. org/10.1073/pnas.1513943113. Lysosomal defects may contribute to the pathogenesis of autoimmunity in lupus.

34. Mauthe M, Orhon I, Rocchi C, Zhou X, Luhr M, Hijlkema KJ, et al. Chloroquine inhibits autophagic flux by decreasing autophagosome-lysosome fusion. Autophagy. 2018;14(8):143555. Available from: https://doi.org/10.1080/15548627.2018. 1474314. Antimalarials may disrupt endosome-lysosome fusion, preventing autophagic flux.

35. Yin $\mathrm{H}, \mathrm{Wu} \mathrm{H}$, Chen Y, Zhang J, Zheng M, Chen G, et al. The therapeutic and pathogenic role of autophagy in autoimmune diseases. Front Immunol. 2018;9:1512. Available from: https://doi. org/10.3389/fimmu.2018.01512, 2018 .

36. Costedoat-Chalumeau N, Amoura Z, Huong DL, Lechat P, Piette JC. Safety of hydroxychloroquine in pregnant patients with connective tissue diseases. Review of the literature. Autoimmun Rev. 2005;4(2):111-5. Available from: https://doi.org/10.1016/j.autrev. 2004.11.009, 2005.

37. Sammartino et al. 2020 American College of Rheumatology Guideline for the Management of Reproductive Health in Rheumatic and Musculoskeletal Diseases. Arthritis \& Rheumatology. 2020; 72(4): 529-556. Available from: https:// doi.org/10.1002/art.41191

38. Devaux CA, Rolain JM, Colson P, Raoult D. New insights on the antiviral effects of chloroquine against coronavirus: what to expect for COVID-19? Int J Antimicrob Agents. 2020;55(5):105938. Available from: https://doi.org/10.1016/j.ijantimicag.2020. 105938, 2020.

39. Wallace DJ, Linker-Israeli M, Metzger AL, Stecher VJ. The relevance of antimalarial therapy with regard to thrombosis, hypercholesterolemia and cytokines in SLE. Lupus. 1993;2 Suppl 1:S13-5. Available from: https://doi.org/10.1177/0961203393002001041, 1993.

40. van den Borne BE, Dijkmans BA, de Rooij HH, le Cessie S, Verweij CL. Chloroquine and hydroxychloroquine equally affect tumor necrosis factor-alpha, interleukin 6 , and interferon-gamma production by peripheral blood mononuclear cells. J Rheumatol. 1997;24(1):55-60. Available from: https://pubmed.ncbi.nlm.nih. gov/9002011/

41. Paton NI, Goodall RL, Dunn DT, Franzen S, Collaco-Moraes Y, Gazzard BG, et al. Effects of hydroxychloroquine on immune activation and disease progression among HIV-infected patients not receiving antiretroviral therapy: a randomized controlled trial. JAMA. 2012;308(4):353-61. https://doi.org/10.1001/jama.2012. 6936.

42. Chiang G, Sassaroli M, Louie M, Chen H, Stecher VJ, Sperber K. Inhibition of HIV-1 replication by hydroxychloroquine: mechanism of action and comparison with zidovudine. Clin Ther. 1996;18(6): 1080-92. Available from: https://doi.org/10.1016/S0149-2918(96) 80063-4, 1996.

43. Ooi EE, Chew JS, Loh JP, Chua RC. In vitro inhibition of human influenza A virus replication by chloroquine. Virol J. 2006;3:39. Available from: https://doi.org/10.1186/1743-422X-3-39, 2006.

44. Shibata M, Aoki H, Tsurumi T, Sugiura Y, Nishiyama Y, Suzuki S, et al. Mechanism of uncoating of influenza B virus in MDCK cells: action of chloroquine. J Gen Virol. 1983;64(Pt 5):1149-56. Available from: https://doi.org/10.1099/0022-1317-64-5-1149, 1983.

45. Wu L, Dai J, Zhao X, Chen Y, Wang G, Li K. Chloroquine enhances replication of influenza A virus A/WSN/33 (H1N1) in dose-, time-, and MOI-dependent manners in human lung epithelial cells A549. J Med Virol. 2015;87(7):1096-103. Available from: https://doi.org/10.1002/jmv.24135, 2015.

46. Vincent MJ, Bergeron E, Benjannet S, Erickson BR, Rollin PE, Ksiazek TG, et al. Chloroquine is a potent inhibitor of SARS coronavirus infection and spread. Virol J. 2005;2:69. Availble from: https://doi.org/10.1186/1743-422X-2-69, 2005.

47. Li W, Moore MJ, Vasilieva N, Sui J, Wong SK, Berne MA, et al. Angiotensin-converting enzyme 2 is a functional receptor for the SARS coronavirus. Nature. 2003;426(6965):450-4. Available from: https://doi.org/10.1038/nature02145, 2003.

48. Takayama K. In vitro and animal models for SARS-CoV-2 research. Trends Pharmacol Sci. 2020 Aug;41(8):513-517. Available from: https://doi.org/10.1016/j.tips.2020.05.005

49. CDC. CDC SARS Response Timeline [Internet\}. 2020. Available from: https://www.cdc.gov/about/history/sars/timeline.htm.

50. Johns Hopkins University of Medicine. Coronavirus Resource Center [Internet]. 2020. Available on: https://coronavirus.jhu.edu/ map.html.

51. Yao X, Ye F, Zhang M, Cui C, Huang B, Niu P, et al. In vitro antiviral activity and projection of optimized dosing design of hydroxychloroquine for the treatment of severe acute respiratory syndrome coronavirus 2 (SARS-CoV-2). Clin Infect Dis. 2020;71(15):732-9. Available from: https://doi.org/10.1093/cid/ ciaa237, 2020.

52. Liu J, Cao R, Xu M, Wang X, Zhang H, Hu H, et al. Hydroxychloroquine, a less toxic derivative of chloroquine, is effective in inhibiting SARS-CoV-2 infection in vitro. Cell Discov. 2020;6:16.

53.• Fan J, Zhang X, Liu J, Yang Y, Zheng N, Liu Q, et al. Connecting hydroxychloroquine in vitro antiviral activity to in vivo concentration for prediction of antiviral effect: a critical step in treating COVID-19 patients. Clin Infect Dis. 2020. Available form: https://doi.org/10.1093/cid/ciaa623. Early SARS-CoV-2 in vitro studies to establish the HCQ dose necessary to achieve antiviral activity in vivo likely did not account for differences between the in vitro assay and the in vivo target tissue.

54. Balevic, S et al. Dr. Balevic, et al, reply. The Journal of Rheumatology. May 2020. Available from: https://doi.org/10. 3899/jrheum.200681. 
55. Gu J, Korteweg C. Pathology and pathogenesis of severe acute respiratory syndrome. Am J Pathol. 2007;170(4):1136-47. Available from: https://doi.org/10.2353/ajpath.2007.061088, 2007.

56. Huang C, Wang Y, Li X, Ren L, Zhao J, Hu Y, et al. Clinical features of patients infected with 2019 novel coronavirus in Wuhan, China. Lancet. 2020;395(10223):497-506. Available from: https://doi.org/10.1016/S0140-6736(20)30183-5, 2020.

57. Chen et al. Clinical and immunologic features in severe and moderate Coronavirus Disease 2019. J Clin Invest. 2020;130(5):26202629. Available from: https://doi.org/10.1172/JCI137244. Highlights role of hyperinflammation and immune system dysregulation in the pathogenesis of COVID-19.

58. Zhao M. Cytokine storm and immunomodulatory therapy in COVID-19: role of chloroquine and anti-IL-6 monoclonal antibodies. Int J Antimicrob Agents. 2020;55(6):105982. Available from: https://doi.org/10.1016/j.ijantimicag.2020.105982.

59. Gautret P, Lagier JC, Parola P, Hoang VT, Meddeb L, Mailhe M, et al. Hydroxychloroquine and azithromycin as a treatment of COVID-19: results of an open-label non-randomized clinical trial. Int J Antimicrob Agents. 2020;56(1):105949. Available from: https://doi.org/10.1016/j.ijantimicag.2020.105949, 2020.

60. Mahévas M, Tran VT, Roumier M, Chabrol A, Paule R, Guillaud $\mathrm{C}$, et al. Clinical efficacy of hydroxychloroquine in patients with covid-19 pneumonia who require oxygen: observational comparative study using routine care data. BMJ. 2020;369:1-9. Available from: https://doi.org/10.1136/bmj.m1844, 2020.

61. Geleris J, Sun Y, Platt J, Zucker J, Baldwin M, Hripcsak G, et al. Observational study of hydroxychloroquine in hospitalized patients with COVID-19. N Engl J Med. 2020;382:2411-8. https://doi.org/ 10.1056/NEJMoa2012410.

62. Rosenberg ES, Dufort EM, Udo T, Wilberschied LA, Kumar J, Tesoriero J, et al. Association of treatment with hydroxychloroquine or azithromycin with in-hospital mortality in patients with COVID-19 in New York State. JAMA - J Am Med Assoc. 2020;323:2493-502. https://doi.org/10.1001/jama.2020. 8630.

63. Paccoud O, Tubach F, Baptiste A, Bleibtreu A, Hajage D, Monsel G, Tebano G, Boutolleau D, Klement E, Godefroy N, Palich R, Itani O, Fayssal A, Valantin MA, Tubiana R, Burrel S, Calvez V, Caumes E, Marcelin AG, Pourcher V Compassionate use of hydroxychloroquine in clinical practice for patients with mild to severe Covid-19 in a French university hospital. Clin Infect Dis. Oxford University Press (OUP); 2020 [cited 2020 Sep 28]; Available from: https://doi.org/10.1093/cid/ciaa791.

64. Arshad S, Kilgore P, Chaudhry ZS, Jacobsen G, Wang DD, Huitsing K, et al. Treatment with hydroxychloroquine, azithromycin, and combination in patients hospitalized with COVID-19. Int J Infect Dis. 2020;97:396-403. Available from: https://doi.org/10.1016/j.ijid.2020.06.099, 2020.

65. Tang W, Cao Z, Han M, Wang Z, Chen J, Sun W, et al. Hydroxychloroquine in patients with mainly mild to moderate coronavirus disease 2019: open label, randomised controlled trial. BMJ. 2020;369:m1849. Available from: https://doi.org/10.1136/ bmj.m1849.

66. Boulware DR, Pullen MF, Bangdiwala AS, Pastick KA, Lofgren $\mathrm{SM}$, Okafor EC, et al. A randomized trial of hydroxychloroquine as postexposure prophylaxis for Covid-19. N Engl J Med. 2020;383: 517-25. https://doi.org/10.1056/NEJMoa2016638.

67. Mitjà $\mathrm{O}$, Corbacho-Monné MB, Ubals MB, Tebe C, Peñafiel $\mathrm{J}$, Tobias A, et al. Hydroxychloroquine for early treatment of adults with mild Covid-19: a randomized-controlled trial. Oriol Mitjà, Omi. Available from: https://doi.org/10.1093/cid/ciaa1009, 2020.

68. Skipper CP, Pastick KA, Engen NW, Bangdiwala AS, Abassi M, Lofgren SM, et al. Hydroxychloroquine in nonhospitalized adults with early COVID-19. Ann Intern Med. 2020;0:1-24. Available from: https://doi.org/10.7326/M20-4207, 2020.

69. Cavalcanti AB, Zampieri FG, Rosa RG, Azevedo LCP, Veiga VC, Avezum A, et al. Hydroxychloroquine with or without azithromycin in mild-to-moderate Covid-19. N Engl J Med. 2020;383:1-12. https://doi.org/10.1056/NEJMoa2019014.

70. Abella BS, Jolkovsky EL, Biney BT, Uspal JE, Hyman MC, Frank I, et al. Efficacy and safety of hydroxychloroquine vs placebo for pre-exposure SARS-CoV-2 prophylaxis among health care workers. JAMA Intern Med Available from. 2020. https://doi.org/ 10.1001/jamainternmed.2020.6319.

71. Chen Z, Hu J, Zhang Z, Jiang S, Han S, Yan D, et al. Efficacy of hydroxychloroquine in patients with COVID-19: results of a randomized clinical trial. Preprint. medRxiv. Apr 10 2020. Available from: https://doi.org/10.1101/2020.03.22.20040758.

72. Magagnoli J, Narendran S, Pereira F, Cummings TH, Hardin JW, Sutton SS, et al. Outcomes of hydroxychloroquine usage in United States Veterans hospitalized with COVID-19. Med (N Y). 2020. Available from: https://doi.org/10.1016/j.medj.2020.06.001.

73. Appelqvist H, Waster P, Kagedal K, Ollinger K. The lysosome: from waste bag to potential therapeutic target. J Mol Cell Biol. 2013;5:214-226. Available from: https://doi.org/10.1093/jmcb/ mjt022, 2013.

74. Furst DE, Lindsley H, Baethge B, Botstein GR, Caldwell J, Dietz F, et al. Dose-loading with hydroxychloroquine improves the rate of response in early, active rheumatoid arthritis: a randomized, doubleblind six-week trial with eighteen-week extension. Arthritis Rheum. 1999;42(2):357-65. https://doi.org/10.1002/15290131(199902)42:2<357::AID-ANR19>3.0.CO;2-J.

75. Balevic SJ, Hornik CP, Green TP, Clowse MEB, Gonzalez D, Maharaj AR, et al. Hydroxychloroquine in patients with rheumatic disease complicated by COVID-19: clarifying target exposures and the need for clinical trials. J Rheumatol. 2020. Available from: https://doi.org/10.3899/jrheum.200493.

Publisher's Note Springer Nature remains neutral with regard to jurisdictional claims in published maps and institutional affiliations. 